\title{
Artificial Intelligence \& Cloud Computing in Environmental Systems-Towards Healthy \& Sustainable Development
}

\author{
P.K. Paul ${ }^{1}$, A. Bhuimali ${ }^{2}$, P.S. Aithal ${ }^{3}$, K.S. Tiwary ${ }^{4}$ and R. Saavedra ${ }^{5}$ \\ ${ }^{1}$ Executive Director, MCIS \& Asst. Professor, Department of CIS, Information Scientist (Offg.) Raiganj University, India \\ ${ }^{2}$ Vice Chancellor, Raiganj University (RGU), West Bengal, India \\ ${ }^{3}$ Vice Chancellor, Srinivas University, Karnataka, India \\ ${ }^{4}$ Dean (Science \& Management), Raiganj University (RGU), West Bengal, India \\ ${ }^{5}$ Director \& Chair (International Programs) Azteca University, Mexico City, Mexico
}

*Corresponding author: pkpaul.infotech@gmail.com

Received: 25 Apr., 2020

Revised: 27 May, 2020

Accepted: 05 June, 2020

\begin{abstract}
Environment is a big venture and aspects and also conveys as a field of study and practice such as Environment Science, Environment Studies, Environment Engineering, Environment Management, etc. Environmental Informatics is another important subject and emerging regarding the IT and Computing solutions in the environment. The merging of environmental areas and Informatics areas are commonly known as Environmental Informatics. Environmental Informatics is the best way for solving technology related issues with educated manpower and further, it uses various kinds of tools, techniques and subtechnologies of Computing and Information Technology in Environment, Ecology and Biological Sciences. The technologies such as Database Technology, Networking Technology, Multimedia Technology, Web Technology, Software Technology are most common and useful in Environment and Ecology related issues, activities and problem solving. In recent past other emerging technologies like Cloud Computing, Artificial Intelligence, Big Data Analytics, Computational Intelligence, Human Computer Interaction, etc. are also being widely used. This paper is dedicated to basic review on Environmental Informatics including its nature, feature, and functions with special reference to the applications of Artificial Intelligence and Cloud Computing.
\end{abstract}

Keywords: Environmental Informatics, Emerging Technologies, Information Science, Ecological Modeling, Artificial Intelligence, Robotics

Environmental Informatics is broader than a similar area Geo Informatics and dedicated in healthy and complete environment related problem solving in different contexts. Therefore, it is required in other areas viz. environment, ecology, agriculture, oceanography, climatology, forestry, anthropology, etc. ${ }^{[1],[5],[9]}$. Here various common and basic Information Technology tools and components are being used such as-
- Database Technology,

- Web Technology,

- Network and Communication Technology,

- Software Technology, etc.

How to cite this article: Paul, P.K., Bhuimali, A., Aithal, P.S., Tiwary, K.S. and Saavedra, R. (2020). Artificial Intelligence \& Cloud Computing in Environmental Systems-Towards Healthy \& Sustainable Development. International Journal of Inclusive Development, 6(1): 69-76.

Source of Support: None; Conflict of Interest: None 
Due to the importance of the Environmental Informatics many educational institutes have started educational programs on Environmental Informatics such as Certificate, Bachelors, Masters, Doctoral, etc internationally. Artificial Intelligence is the technology which acts like a human or integrated with intelligence. Artificial Intelligence applications in the environment and ecology are increasing in wider sections and Cloud Computing is also emerging for the storage, network and platform related solutions ${ }^{[3],[12],[23]}$.

\section{Objective}

The paper entitled 'Artificial Intelligence \& Cloud Computing in Environmental Systems - Towards Healthy \& Sustainable Development, deals with following aims and objectives-

- To get the knowledge of Environmental Informatics such as its background, features and nature, etc.

- To learn about the common technologies used in Environmental Informatics practice and also emerging and latest technologies.

- To learn about Artificial Intelligence its foundation, features and functions in a general context.

- To know about the basics of Cloud Computing including its features, functions, types, and basic services in respect of Environmental solutions or Environmental Informatics practice.

\section{Environmental Informatics: The fusion of Environment and Information Science}

Environmental Informatics is dedicated to the solution of the energy, environmental, agriculture and ecological systems, etc by various kinds of IT and Computing tools and also environmental decision support systems. Environmental Systems and Services may be rendered from technologies like GIS, Remote Sensing, GPS, etc., directly and indirectly ${ }^{[6],[21]}$. Environmental Informatics basically uses the tools and technologies for various activities but not limited to the following-

- Environmental Informatics is very much needed in the aspects viz. designing, developing, modeling as well as the implementation of chemical, biological, environmental process, etc.
- Regarding the development of the websites on the environment, ecology, agriculture, etc also Environmental Informatics is very worthy.

- In the development of the modeling of biotechnological systems also Environmental Informatics is being widely practiced.

- Various kinds of multimedia tools, graphics, 3D tools, visualization systems, etc. are also very important in environmental systems and in this context Environmental Informatics tools may be considered as important.

The field is widely applicable in diverse areas of environment viz. town and urban planning, ocean management, forest management, agricultural systems, biodiversity management, etc and for such benefits and functions the field Environmental Informatics is being useful in different sectors.

\section{Artificial Intelligence and Cloud Computing: Foundation and Applications}

Artificial Intelligence is dedicated to developing intelligence in the systems and also in the products and services. Artificial Intelligence is performed by machines and act like humans and also able to mimic their actions; further, it is able to learning and problem-solving affairs. Artificial Intelligence can rationalize and take actions to achieve a desired or specific goal and applicable in various areas, different sectors and industries. In a wide range of areas and sectors such as healthcare, governance, business, administration, transport and tourism, education, etc. Artificial Intelligence is widely useful. Different kinds of automated machines, intelligent devices, etc. are the major examples of Artificial Intelligence. The following can be considered as important in respect of Artificial Intelligence applications viz.-

- Artificial intelligence is very much concerned with the simulation and also acting like human intelligence in various types of devices and machines.

- Artificial Intelligence is very much concerned about learning, reasoning, and perception.

- Weak Artificial Intelligence and strong Artificial Intelligence are two major tasks in AI which are more complex and human-like $\mathrm{e}^{[2],[11],[22] \text {. }}$ 
Weak Artificial Intelligence is concerned it is required in designing of the system that can do a particular job. Strong Artificial Intelligence is more intelligent and able to perform like humans and able in more complex and complicated system development. Therefore in Strong AI complex as well complicated systems are required to solve the problem without having a person.

Machine Learning is considered as an important sub set of Artificial Intelligence and here various statistical techniques are used with the affairs of computation, decision making, etc. Arthur Samuel, in the year 1959 coined the term first with deep involvement in exploring the study and construction of algorithms; further Machine Learning have a different kind of approaches viz.-

- Decision and Association Tree Learning

- Artificial Neural Networks

- Deep Learning and Clustering

- Inductive Logic Programming

Deep Learning is also part of Machine Learning and considers as allied to Artificial Intelligence. Various architectures are considered as important in deep learning like deep neural networks, deep belief networks, recurrent neural networks, etc. ${ }^{[8],[15]}$. These are useful in a wide range of areas like-

- Computer vision and NLP

- Automatic speech and Image recognition

- Visual art processing

- Bioinformatics

- Mobile advertising

- Image restoration, etc.

Therefore, the applications of Artificial Intelligence including Robotics, Machine Learning, etc. are well applicable in Environmental related problems and issues including complete Environmental Informatics solutions.

Similar to Artificial Intelligence another important technology is Cloud Computing also very prominent in environmental solutions and services. Cloud Computing and Technology is applicable in many conventional information technology practices and it offers solutions to the networks, software, applications, database and storage, infrastructure related services.
- Cloud Computing is concerned with the importance in three segments viz. application, storage and connectivity.

- It depends on various kinds of internet and networks related services all time depending upon users need.

- The Grid Computing and Virtualization Technology is very important in the Cloud Computing platform.

- Cloud Computing needs continuous, robust internet as well as broadband services.

- With the help of Cloud Computing, hassle free engagement of information technology becomes possible and smarter.

- Cloud Computing offers the easiest connectively as well as services opt for its users.

Cloud Computing is emerging communication technology and helps in easier communication. It helps in making of healthy and digital society with only knowledge based services and promoting the same $^{[2],[23]}$. Knowledge Management is also very important with the help of Cloud Computing since it is an important utility computing and can also consider as emerging technological service providers; directly and indirectly. With Cloud Computing easiest migration as well as deployment becomes possible. Cloud Computing is applicable in diverse areas including business, government, education, transportation and so on. Similarly, in Environment and Ecological areas also use of the Cloud Computing systems is noticeable. Information is driving force in any sector and with the Cloud Computing better solutions and systems become possible effectively. Governments of various countries are doing efforts, helps and promotion in Cloud Computing in diverse areas due to its importance ${ }^{[14],[20]}$.

\section{Artificial Intelligence and Cloud Computing in Environmental Systems: The Multiple Concerns}

Artificial Intelligence and Cloud Computing are important in the Information Technology field and there are many applications possible in the environment, ecology, and allied areas and the applications and integration are increasing day by day viz. (also refer Fig. 1 depicted various concern of AI applications in Environment and Ecology)- 

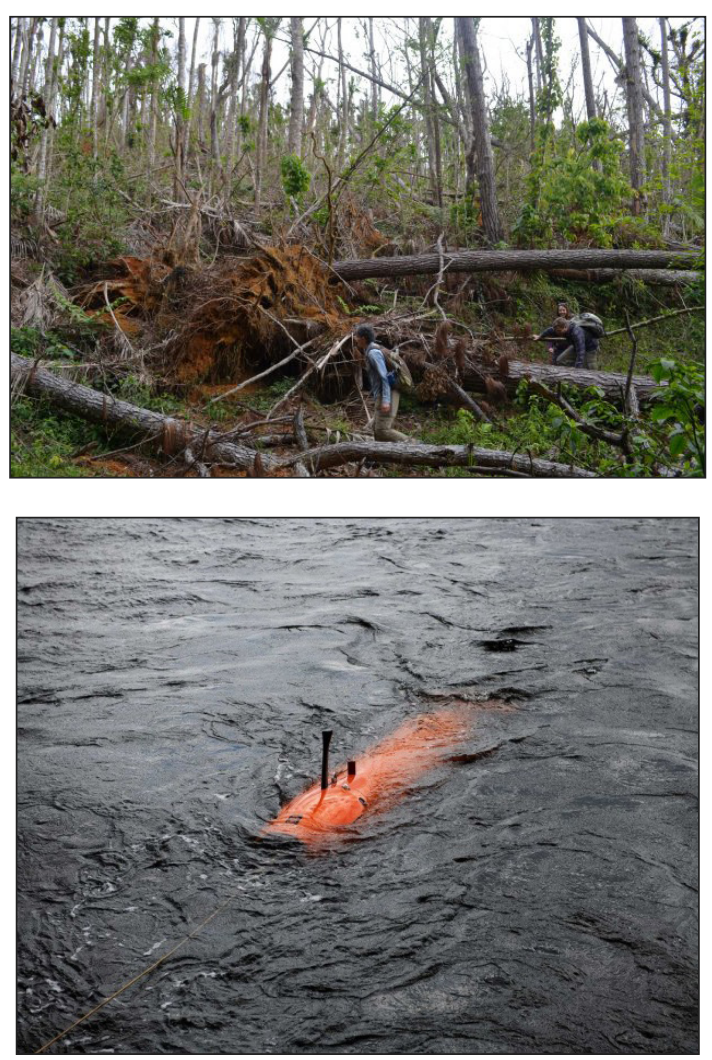
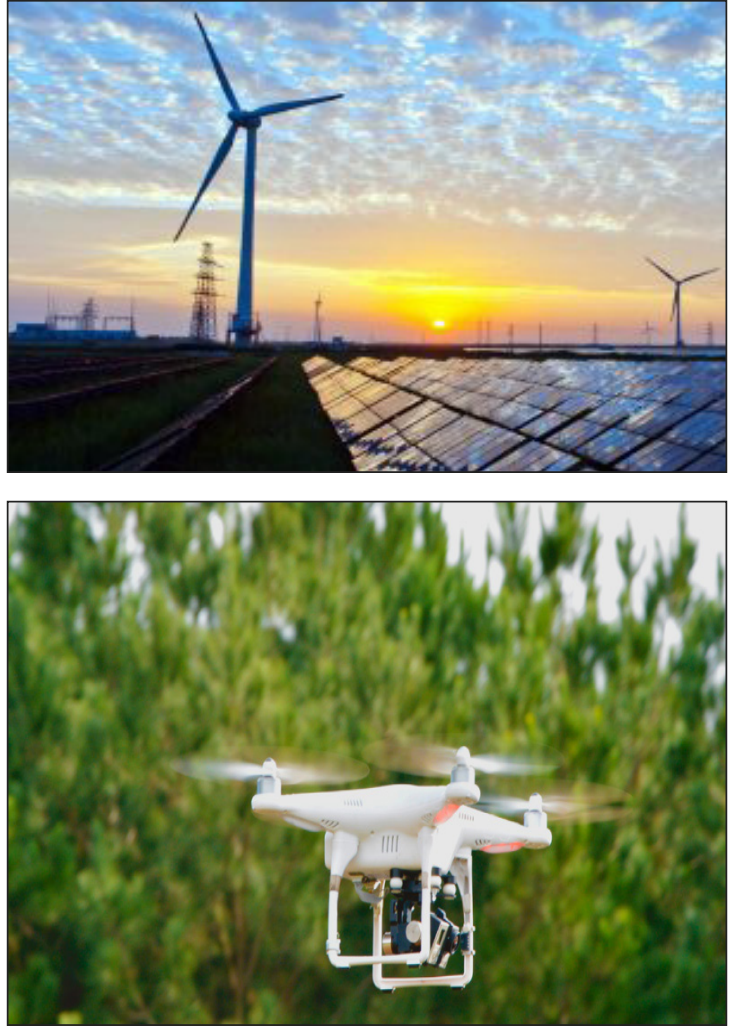

Fig. 1: Depicted various concerns of AI applications in Environment and Ecology

Every day the planet become warm and climates are also changing; according to a report in the year 2016 there was 772 weather and disaster related event and the number was increased three times what happened in the year 1980 in this regard. Due to this activity around $20 \%$ of the species currently are facing problems and it may reach around 50\% in the year 2100 according to the experts. Moreover, the temperature of the earth can also rise to $3^{\circ} \mathrm{C}$ higher than in pre-industrial times. Here Artificial Intelligence and similar Computing system are worthy to manage the climate change and also to protect the planet. As Artificial Intelligence is worthy and can sense their environment, think, learn, and act based on need. Such practices also noted, examined and practiced different parts of the globe including in India, Norway, China, etc. Here Cloud Computing is also worthy to store the data of each and every important moment and context and also in respect of communication and networking among the weather and climate management stations.

According to the researchers, it is also noted that with the use of Artificial Intelligence tropical cyclones can be identified and managed. Further accuracy in identifying tropical cyclones, weather fronts including atmospheric rivers becomes easy. And with this kind of practice here improving weather forecasts become perfect ${ }^{[4],[19]}$.

With the help of Artificial Intelligence, Robotics and Machine learning since the prediction is possible in many contexts therefore these are also helpful in alert during the disaster or keep people safe.

Many experts and organizations (especially Microsoft) believe that Artificial Intelligence since associated with machine learning and deep learning therefore is a game changer for the climate and ecological aspects and concern. Microsoft, Google, IBM has initiated many projects which are very much worthy in environmental management and monitoring.

After any natural disaster viz. cyclone in the forest, it may be difficult to learn about the actual trees affected since from the satellite all may look similar, only with human eyes, such differences can be possible to learn but with AI integrated technologies it is become very easy to find out the latest happening or actual affected tress than the traditional system. 
Artificial Intelligence Systems are also worthy in renewal energy management and enhancement of the energy perfectly; further, it can handle power fluctuations and improve energy storage as well, as far as the latest research is concerned.

Machine learning and artificial intelligence also help in the Energy Management by providing quick decision making support by its intelligence regarding the vulnerabilities of the grid, advance failure and also restoring power systems and therefore AI can be also suitable in respect of automatically manage renewable energy systems immediately without interruption of the services and human engagement $t^{[2],[15]}$.

In the wind based Energy Systems also AI and similar technologies are very much important and valuable for clearing the machines from the dust and also keep them ready in every condition.

Artificial Intelligence and similar technologies are very much important in making urban and rural areas much more advanced and smarter. Here different devices are responsible for making lives easy including help in floods, air ventilation, monitoring, and feedback, etc. Here AI based systems collect the data and help in making life become normal and healthy in a different context. City based air pollution tracking becomes possible with Robotics supported intelligent systems which ultimately helps in societal development in many contexts. Here Cloud Computing based systems are able in storing data and transfer them accordingly.

Machine Learning based systems are able in guiding for suitable places for the tree plantation from its database and intelligence systems and here Cloud Computing based systems are worthy and very much important.

Intelligent sensors become important and able in the collection of real time data regarding the crop moisture, composition of the soil and also temperature systems. Therefore directly and indirectly it helps in environmental management and monitoring. In the urbanization and in agricultural management therefore it helps in increased efficiency, enhanced yields, and in other contexts helps in reduced water, fertilizer and pesticide uses ${ }^{[7],[20]}$.
In Ocean Management also Artificial Intelligence and similar systems are worthy and important in case of tracking of a ship and monitoring, ocean mining, fishing and so on. And these are rising gradually. Further in coral bleaching or the outbreak of a marine disease also Artificial Intelligence Systems are worthy and important. Here the use of Cloud Computing is very important and worthy in respect of data management and collection of real time data.

In better and healthy transportation systems also AI, Robotics and allied technologies are important these days. Since transportation is the part of Environment therefore healthy, planned and sustainable transportation is always perfect for the human being, citizens and environment. In the traffic, automated cars, etc. sensor and camera integrated vehicles are also increasing. Here autonomous AI-driven shared transportation systems may replace personal vehicles and for collection of the data, information, etc. cloud computing are worthy and important.

Climate change is an emerging issue worldwide and this condition is rising globally and here climate models are very much important in predictions and for such climate model development, Artificial Intelligence and Similar Systems are worthy and important. The Cloud Computing based tools and systems therefore worthy and important in this regard. Further $\mathrm{AI}$ is required to determine which climate models are reliable ${ }^{[11],[17]}$.

In atmospheric and ocean dynamics and ocean and atmospheric chemistry, into their calculations also Artificial Intelligence is worthy and important here IaaS, PaaS, SaaS are worthy in data and information management in this regard.

The monitor ecosystems and wildlife management become possible with Artificial Intelligence and similar systems and their interactions. The realtime satellite collected data or sensor collected data may be worthy in forest management. The drinking water quality, water use, detecting of the underground leaks finding vulnerabilities in disaster planning become possible with the Artificial Intelligence and similar systems. Hence the realtime disaster response coordination is effective and easy with this. 


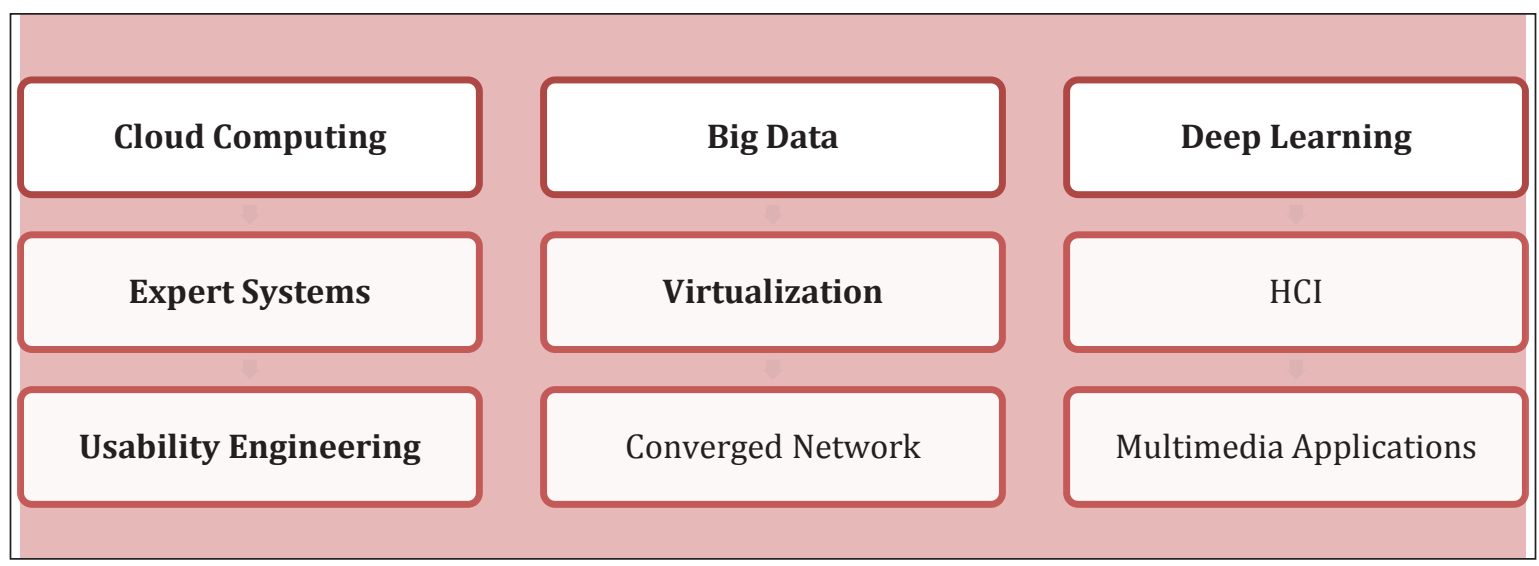

Fig. 2: Allied Technologies of AI that helps in Environmental Informatics practice more effective

\section{Environmental Informatics, AI: The Aspects of Land, Air and Water as a Core Concern}

Environmental Informatics is the emerging field for the development of sustainable and healthy environmental development using technologies. So far, we already learn about various technologies and systems and in this regard,it is worthy to note that Artificial Intelligence including other allied technologies viz. Robotics, Machine Learning, Deep Learning, etc. very much important in following three major concerns i.e. Land, Air and Water. However various other allied technologies (refer Fig. 2) are also worthy in regard to perfect AI operations ${ }^{[5],[13]}$.

\section{Land}

Applications of Artificial Intelligence and allied technologies are very much worthy in Land related activities including soil management, soil pollution, intensive and healthy agricultural development, etc. The agriculture truly depends on soil and in this context, proper soil identification, land identification and management many ways depend on AI and Robotics. Here robotic based systems and products provide automated data collection and all such are stored in the databases and decision. With the support of AI further, therefore, land-friendly crops become possible. AI monitoring thus helps in effective farm management and development of the Ecosystem and habitats around the world. Here AI based tools viz. AI integrated drones can also be treated as worthy. Further, in todays context, plant disease detection, poacher root prediction, erosion monitoring, species identification, and animal migration is important and become healthy and considered important even World Economic Forum expressed the same. Here all the data and infrastructure related solutions are perfectly possible with cloud computing.

\section{Air}

As far as Air Management is concerned Artificial Intelligence is considered as an important tool for the Air related activities in different context. Artificial Intelligence and allied technologies help in better monitoring of pollution of the air. Further, it is also required in faster and more accurate air pollution identification. For the gas leak identification also smart sensors enabled AI to become more objective prevention. Air pollution problems more quickly and more efficiently become possible to find out with AI based systems. In the reduction of the harmful emissions also $\mathrm{AI}$ is worthy. Since the air population is a dangerous global crisis and to incorporate World Health Organization (WHO) air quality guidelines AI can be treated as important and healthy. AI supported autonomous vehicles can also able to reducing oil consumption and associated greenhouse gas emissions by 2 to $4 \%$ according to the expert. And Cloud Computing is here possible to hold data collection and management effectively ${ }^{[7],[16]}$.

\section{Water}

In Water related management and quality monitoring also Artificial Intelligence and allied technologies are useful in a different context. Since water is very important in survive therefore it is worthy in proper and healthy Water System development, monitoring and management. The cleanliness of the water, 
identification of water depth become possible with AI supported systems. Further in the areas of ocean water management for the lives of the ocean $\mathrm{AI}$ and allied technologies including Cloud Computing and Virtualization here become worthy and important.

\section{CONCLUSION}

AI is an important and helpful tool and has been able in making of significant amends in respect of land, air, and water and clean it up for a healthier planet. Environmental Informatics is growing internationally and different branches within Environmental Informatics are rising for the development of societal and anthropological improvement. Here various kinds of Emerging technologies such as in addition to AI and ML are important and worthy viz. big data analytics, cloud computing, IoT, converged network and communication. It is important to note that Artificial Intelligence applications are rising internationally but mostly in developed countries. Since Environment is a global concern and problem therefore other countries also need to hold proper effort in this regard. Further government bodies, institutions and policymakers need to introduce proper steps for better AI and allied technological integration in the environment and ecology and also in other subjects and areas viz. agriculture, oceanography, climatology, forestry, anthropology. Educational institutes, research centres also need to hold proper educational programs for the development of manpower and solve HR related issues.

\section{REFERENCES}

1. Allen, T.F., Giampietro, M. and Little, A.M. 2003. Distinguishing ecological engineering from environmental engineering. Ecological Engineering, 20(5): 389-407.

2. Dayal, I. 2002. Developing management education in India. Journal of management Research, 2(2): 98.

3. Goldberg-Kahn, B. and Healy, J.C. 1997. Medical informatics training in pathology residency programs. American Journal of Clinical Pathology, 107(1): 122-127.

4. Gupta, D. and Gupta, N. 2012. Higher education in India: structure, statistics and challenges. Journal of Education and Practice, 3(2). 17-24.

5. Henricks, W.H., Boyer, P.J., Harrison, J.H., Tuthill, J.M. and Healy, J.C. 2003. Informatics training in pathology residency programs: proposed learning objectives and skill sets for the new millennium. Archives of Pathology $\mathcal{E}$ Laboratory Medicine, 127(8): 1009-1018.
6. Kapur, D. and Mehta, P.B. 2004. Indian higher education reform: From half-baked socialism to half-baked capitalism. Center for international development working paper, 103.

7. Nambissan, G.B. and Rao, S. (Eds.). 2013. Sociology of education in India: Changing contours and emerging concerns. New Delhi: Oxford University Press.

8. Nikolov, R. 1987. Integrating informatics into the curriculum. Education and Computing, 3(3): 269-74.

9. Paul, P.K. and Poovammal, E. 2013. Information Service Vis-a-Vis Online and Cloud Environment in $21^{\text {st }}$ Century: Promoting Environmental \& Bio Informatics. Journal of Chemical and Pharmaceutical Sciences, 9(4): 3164-3168.

10. Paul, P.K. 2013. MSc-Information Science [Geo Informatics]: Overview emphasizing two proposed curriculum for sophisticated GeoSpatial development. International Journal of Pharmaceutical and Biological Research (IJPBR), 4(5): 218-227.

11. Paul, P.K., Jhuma Ganguly. and Ghosh, M. 2013. Chemical Information Management powered by ChemoInformatics: Possibilities and opportunities emphasizing need and way in Academics and Universities. Current Trends in Biotechnology and Chemical Research, 3(2): 137-141.

12. Paul, P.K. and Aithal, P.S. 2017. Informatics as a Branch in Indian Academics with Case of Private Universities: Emphasizing Biological Information Sciences. Current Trends in Biotechnology and Chemical Research, 7(1-2): 37-42.

13. Paul, P.K., Ricardo, Saavedra, Aithal, P.S., Bashiru, Aremu. and Baby, Pappachan. 2020. Environmental Informatics: Potentialities in iSchools and Information Science \& Technology Programs - An Analysis. International Journal of Management, Technology, and Social Sciences (IJMTS), 5(1): 238-250.

14. Paul, P.K., Aithal, P.S., Bhuimali, A., Tiwary, K.S., Saavera, R. and Aremu, B. 2020. Geo Information Systems \& Remote Sensing: Applications in Environmental Systems \& Management. International Journal of Management, Technology, and Social Sciences (IJMTS), 5(2): 11-18.

15. Paul, P.K. and Aithal, P.S. 2020. Environmental Informatics and its Features, Functions and Stakeholders: $A$ Comprehensive Overview. Educational Quest: An Int. J. of Education and Applied Social Science, 11(1): 01-05.

16. Paul, P.K., Bhuimali, A., Aithal, P.S., Tiwary, K.S. and Sinha, R.R. 2020. Environmental Informatics: Educational Opportunities at Bachelors level-International Context and Indian Potentialities. International Journal of Applied Engineering and Management Letters (IJAEML), 4(1): 243256.

17. Paul, P.K., Aithal, P.S. and Bhuimali, A. 2020. Environmental Informatics and Educational Opportunities in Post Graduate level-Indian Potentialities based on International Scenario. IRA-International Journal of Management E Social Sciences, 16(2): 45-58.

18. Paul, P.K., Aithal, P.S., Bhuimali, A., Tiwary, K.S. and Deka, G.C. 2020. Environmental Informatics Vis-à-Vis Big Data Analytics: The Geo-Spatial \& Sustainable Solutions. 
International Journal of Applied Engineering and Management Letters (IJAEML), 4(2): 31-40.

19. Sood, R. and Adkoli, B.V. 2000. Medical education in India-problems and prospects. I Indian Acad. Clin. Med., 1(3): 210-212.

20. Sohani, N. and Sohani, N. 2012. Developing interpretive structural model for quality framework in higher education: Indian context. Journal of Engineering, Science $\mathcal{E}$ Management Education, 5(2): 495-501.

21. Supe, A. and Burdick, W.P. 2006. Challenges and issues in medical education in India. Academic Medicine, 81(12): 1076-1080.
22. Tayade, M.C. and Kulkarni, N.B. 2011. The Interface of technology and medical education in India: current trends and scope. Indian Journal of Basic $\mathcal{E}$ Applied Medical Research, 1(1): 8-12.

23. Tilak, J.B. 2008. Transition from higher education as a public good to higher education as a private good: The saga of Indian experience. Journal of Asian Public Policy, 1(2): 220-234. 